showed persistent occlusion of the left carotid artery 2 weeks after surgery, although the artery later regained its continuity to the aorta (Figure 2). As of 6 months after the surgery, the patient is doing well. He can move his neck with no restriction.

\section{DISCUSSION}

The management of patients with acute type A dissections complicated by cerebral malperfusion remains challenging. ${ }^{1}$ Although favorable results of immediate central aortic repair have been reported in recent years, ${ }^{1,3}$ a significant number of patients remain disabled, ${ }^{1,3}$ and some have shown exacerbation and eventual death. ${ }^{1}$

In contrast with malperfusion syndrome involving the coronary arteries or iliofemoral arteries, vascular reconstruction has almost never been performed for carotid arteries. ${ }^{4}$ There are 2 main reasons for this. First, occlusion of the carotid vessels is resolved in most cases after completion of routine central aortic repair. Second, revascularization therapy after acute ischemic stroke is often ineffective and can even harm some patients. ${ }^{5}$

In regard to the first point, it now is clear that some carotid arteries remain occluded after central aortic repair. ${ }^{1}$ These patients tend to have poor postoperative courses. ${ }^{1}$ Intuitively, this case was thought to have a high probability of persistent occlusion considering the long and thrombosed occlusive lesion and the absence of backflow from the orifice despite continuous distal carotid artery perfusion.

In regard to the second point, this patient was judged to be a good candidate for revascularization because he presented early after the onset of symptoms. Although it is not clear which patients will benefit specifically from this additional surgical revascularization for an aortic dissection, general guidelines about patient selection for reperfusion therapy in acute ischemic stroke can be used as a reference at this time. ${ }^{5}$

Additional imaging tests may be necessary for carotid vascular reconstruction, and these tests may unduly delay surgery in certain institutions. Given the poor natural course of acute type A dissection, the judgment to plan aortocarotid bypass should be individualized.

\section{CONCLUSIONS}

Aortocarotid bypass was performed in a patient with type A acute aortic dissection with good results. On the basis of accumulating evidence, we believe it is reasonable to perform vascular reconstruction in the carotid vessels in selected cases.

\section{References}

1. Morimoto N, Okada K, Okita Y. Lack of neurologic improvement after aortic repair for acute type A aortic dissection complicated by cerebral malperfusion: predictors and association with survival. J Thorac Cardiovasc Surg. 2011;142:1540-4.

2. Di Eusanio M, Tan ME, Schepens MA, Dossche KM, Di Bartolomeo R, Pierangeli A, et al. Surgery for acute type A dissection using antegrade selective cerebral perfusion: experience with 122 patients. Ann Thorac Surg. 2003;75:514-9.

3. Estrera AL, Garami Z, Miller CC, Porat EE, Achouh PE, Dhareshwar J, et al. Acute type A aortic dissection complicated by stroke: can immediate repair be performed safely? J Thorac Cardiovasc Surg. 2006;132:1404-8.

4. Geirsson A, Szeto WY, Pochettino A, McGarvey ML, Keane MG, Woo YJ, et al. Significance of malperfusion syndromes prior to contemporary surgical repair for acute type A dissection: outcomes and need for additional revascularizations. Eur J Cardiothorac Surg. 2007;32:255-62.

5. Adams HP Jr, del Zoppo G, Alberts MJ, Bhatt DL, Brass L, Furlan A, et al. Guidelines for the early management of adults with ischemic stroke: a guideline from the American Heart Association/American Stroke Association Stroke Council, Clinical Cardiology Council, Cardiovascular Radiology and Intervention Council, and the Atherosclerotic Peripheral Vascular Disease and Quality of Care Outcomes in Research Interdisciplinary Working Groups: The American Academy of Neurology affirms the value of this guideline as an educational tool for neurologists. Circulation. 2007;115:e478-534.

\title{
Single-stage subchordal resection and reconstruction of idiopathic laryngotracheal stenosis in a male patient
}

\author{
Sina Ercan, MD, ${ }^{\mathrm{a}}$ İsmail Koçak, MD, ${ }^{\mathrm{b}}$ and Ferda Özkan, MD, ${ }^{\mathrm{c}}$ Istanbul, Turkey
}

From the Departments of Thoracic Surgery, ${ }^{\mathrm{a}}$ Otorhinolaryngology, ${ }^{\mathrm{b}}$ and Pathology, Yeditepe University Hospital, Istanbul, Turkey.

Disclosures: Authors have nothing to disclose with regard to commercial support.

Received for publication Aug 12, 2011; accepted for publication Oct 20, 2011; available ahead of print Nov 16, 2011.

Address for reprints: Sina Ercan, MD, Associate Professor of Thoracic Surgery, Department of Thoracic Surgery, Yeditepe University Hospital, Devlet Yolu Ankara Cad No 102-104 Icerenkoy Atasehir 34752, Istanbul, Turkey (E-mail: sinercan@ yahoo.com).

J Thorac Cardiovasc Surg 2012;143:978-80

$0022-5223 / \$ 36.00$

Copyright (c) 2012 by The American Association for Thoracic Surgery

doi:10.1016/j.jtcvs.2011.10.040
Idiopathic laryngotracheal stenosis (ILTS) is a rare condition of inflammatory fibrotic stenosis of the subglottic airway that is mostly circumferential and centered in the cricoid cartilage. To date, the largest series of patients with ILTS has been reported by Ashiku and colleagues. ${ }^{1}$ Patients with ILTS have no recent history of intubation, trauma, or intervention to their airways. Patients with subglottic or tracheal stenosis but with no infectious and vasculitic pathologies, such as Wegener granulomatosis, relapsing polychondritis, polyarteritis, scleroderma, or 

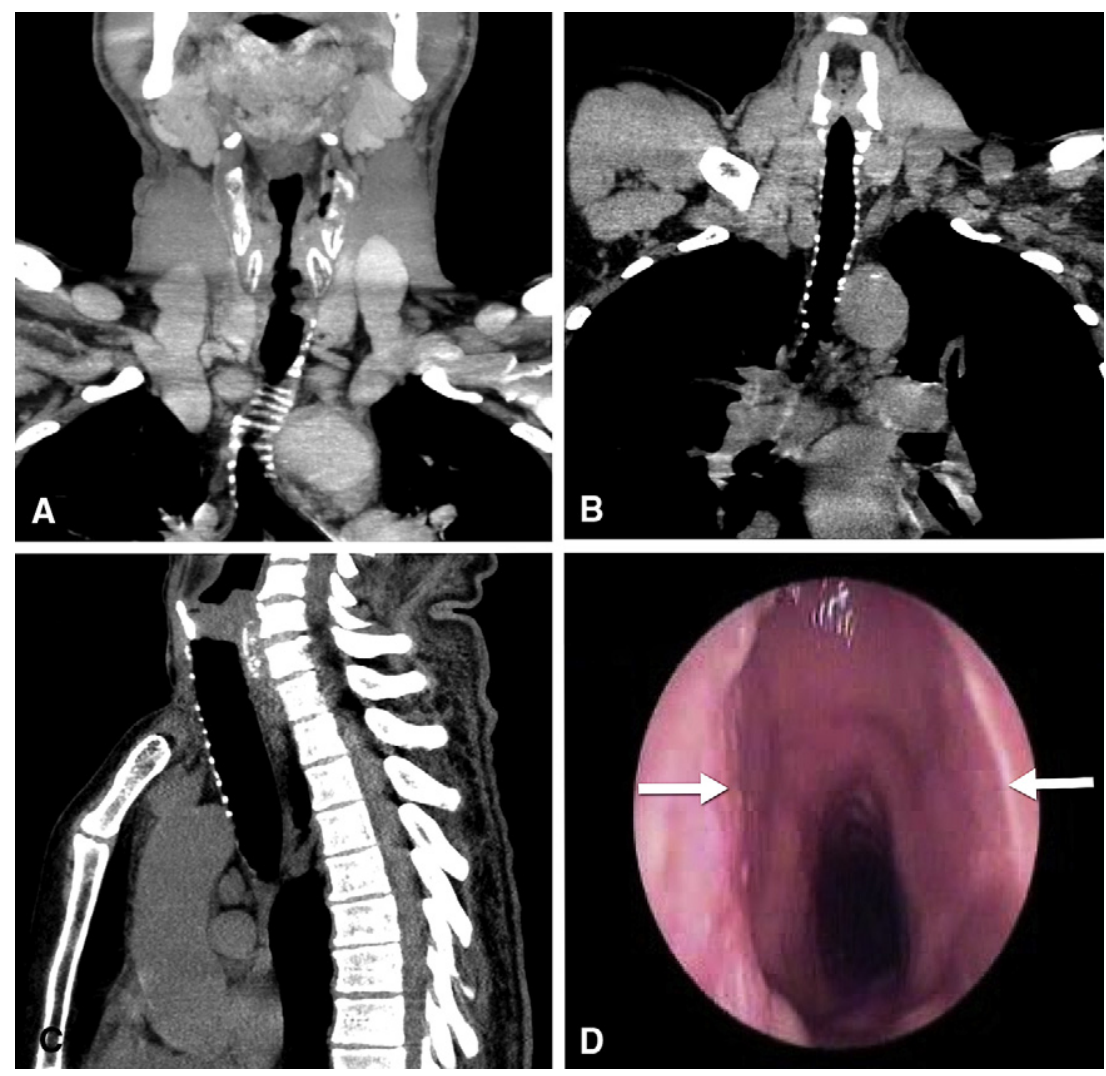

FIGURE 1. A, Coronal section of idiopathic laryngotracheal stenosis in subglottic airway. B and C, Coronal and sagittal section at postoperative 9th month after a subglottic resection and reconstruction. D, Bronchoscopic appearance of anastomosis level immediately below the vocal cords at 6th postoperative month (white arrows).

sarcoidosis, have been considered in the literature to have ILTS. ILTS is seen almost exclusively in female patients, with only 7 reported male patients among 226 cases found in the English language literature. Here we report the 8th male patient with ILTS.

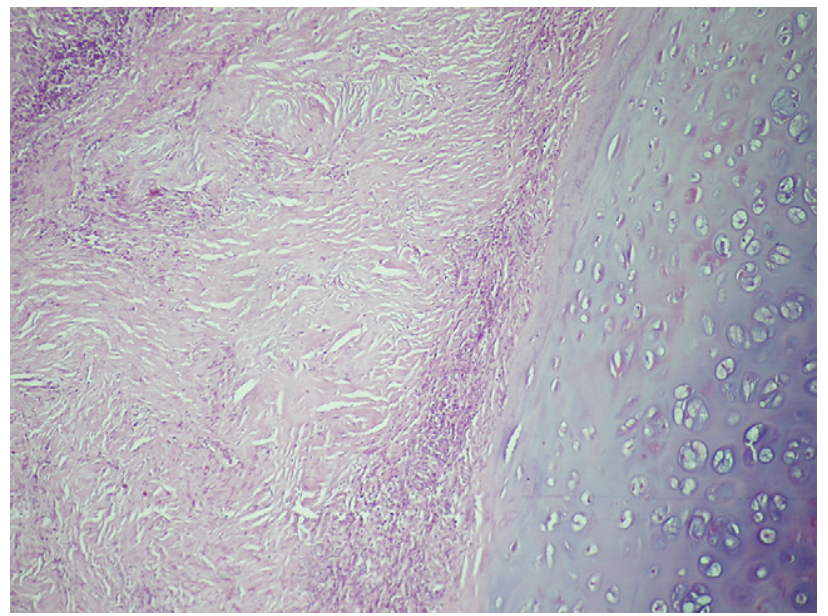

FIGURE 2. Intense subchondral fibrosis with inflammation (hematoxylin and eosin, original magnification $\times 100)$.

\section{CLINICAL SUMMARY}

A 52-year-old male patient had the symptoms of progressive dyspnea with stridor on exertion, hoarse voice, and finally noisy breathing at rest since 2007. Because of his persistent symptoms, in 2009 he underwent 2 endoscopies and a surgical intervention by an otorhinolaryngologist to decompress the vocal cord edema. Biopsy specimens showed nonspecific chronic inflammation, with squamous epithelium and scattered eosinophils. Amyloidosis and malignancy were ruled out by immunohistochemical testing. The patient then came to the otorhinolaryngology department at our institution and underwent a workup for gastroesophageal reflux disease. $\mathrm{He}$ was treated with proton-pump inhibitors and antibiotics for antral gastritis with Helicobacter pylori positivity and with corticosteroids for subglottic stenosis. Despite treatment, his respiratory symptoms persisted without any improvement. Computed tomography showed 9-mm thickened lateral walls immediately below the vocal cords, leaving a narrow central air corridor (Figure 1, A). Stenosis became circumferential at the cricoid level, with a 6-mm central opening. The patient was then referred for a consult with thoracic surgery. 
Wegener granulomatosis was ruled out both clinically and with negative antineutrophil cytoplasmic antibody titers. The patient's significant subglottic inflammation gradually subsided before surgical resection. He then underwent a single-stage laryngotracheal resection of a $3.5-\mathrm{cm}$ segment that included the anterolateral cricoid ring. The anteroinferior margin of thyroid cartilage was trimmed for $2 \mathrm{~mm}$ to elongate the anteroposterior anastomotic diameter for $3 \mathrm{~mm}$ (Figure 1, $B$ and $C$ ). Primary thyrotracheal anastomosis was then performed with 4-0 interrupted Vicryl sutures (Ethicon, Inc, Somerverville, NJ), and a T-tube was placed. The T-tube was removed at the 3rd month, and bronchoscopy at the 6th month showed excellent healing with normal airway diameter (Figure 1,D). The pathologic examination revealed intense fibrosis and inflammation (Figure 2). The patient is free of symptoms at the 17 th postoperative month.

\section{DISCUSSION}

Typically, ILTS is a diagnosis made by ruling out the other possible causes, with the list headed by Wegener granulomatosis. Although laryngotracheal vasculitic involvement is common in Wegener granulomatosis, findings are mostly nonspecific, and this cause should therefore be ruled out preoperatively by checking antineutrophil cytoplasmic antibody. Our patient did not have any clinical findings of Wegener granulomatosis or any other collagen vascular disease, and results were negative for both cytoplasmic and perinuclear antineutrophil cytoplasmic antibody types. Among other possible causes of benign laryngotracheal stenosis are infections, previous trauma (either surgical or by intubation), inhalational burns, irradiation, amyloidosis, and congenital causes, none of which were present in our patient.

This disease shows a strong, unexplained tendency to affect women. In contrast to Ashiku and colleagues, ${ }^{1}$ Dedo and associates ${ }^{2}$ have opined that ILTS is a slowly progressive inflammatory process. They also found support for a female hormonal cause in that the recurrence of stenosis slowed down in older, specifically postmenopausal, women. However, Dedo and associates ${ }^{2}$ and others ${ }^{3}$ failed to find estrogen receptors in the stenotic tissue samples.

Gastroesophageal reflux disease has also been considered in the etiology of ILTS, ${ }^{3}$ with some reports of improvement of ILTS with antireflux therapy. ${ }^{4}$ Continued rarity of ILTS cases despite continuously increasing gastroesophageal reflux disease and intensive endoscopic surveillance programs, however, do not support the role of reflux in etiology of ILTS. Because of its equal incidence in both sexes, gastroesophageal reflux disease also does not explain the strong preponderance of ILTS among female patients. Our patient's respiratory symptoms did not improve with antireflux treatment.

Extent of the disease may change from a very short circumferential weblike cicatrice to several centimeters of concentric fibrotic narrowing, mostly centralized at the cricoid level. We believe that the extent of the pathology should dictate the mode of treatment. Long-running debate regarding the use of local or systemic corticosteroids in the treatment of benign airway stenosis has never yielded an irrefutable proof of persistent benefit. ${ }^{1-3}$ Perotin and coworkers $^{5}$ reported safe and efficient initial treatment with endoscopic dilation, laser, and electrocoagulation; however, $87 \%$ of their patients had recurrence in 5 years. Although weblike short lesions can be treated endoscopically, longer lesions, especially in an immediate subglottic location, are better treated with surgical resection with primary end-to-end anastomosis.

\section{References}

1. Ashiku SK, Kuzucu A, Grillo HC, Wright CD, Wain JC, Lo B, et al. Idiopathic laryngotracheal stenosis: effective definitive treatment with laryngotracheal resection. J Thorac Cardiovasc Surg. 2004;127:99-107.

2. Dedo HH, Catten MD. Idiopathic progressive subglottic stenosis: findings and treatment in 52 patients. Ann Otol Rhinol Laryngol. 2001;110:305-11.

3. Valdez TA, Shapshay SM. Idiopathic subglottic stenosis revisited. Ann Otol Rhinol Laryngol. 2002;111:690-5.

4. Terra RM, de Medeiros IL, Minamoto H, Nasi A, Pego-Fernandes PM, Jatene FB. Idiopathic tracheal stenosis: successful outcome with antigastroesophageal reflux disease therapy. Ann Thorac Surg. 2008;85:1438-9.

5. Perotin JM, Jeanfaivre T, Thibout Y, Jouneau S, Lena H, Dutau H, et al. Endoscopic management of idiopathic tracheal stenosis. Ann Thorac Surg. 2011;92: 297-301. 